\title{
Transforming Pedagogies in Australian Schools amid the COVID-19 Pandemic: An Activity Theoretic Reflection
}

\author{
Clarence $\mathrm{Ng},{ }^{1}$ Peter Renshaw ${ }^{2}$
}

1. Australia Catholic University, Brisbane, QLD 4072, Australia

2. University of Queensland, Brisbane, QLD 4000, Australia

\begin{abstract}
Learning from home" was a collective response to school closure in Australia amid the COVID-19 pandemic. In this paper, we offer a description of the learning-from-home event, highlighting changes that were required of teachers, students and parents. Drawing on Engeström's cultural-historic activity theory, we reflect on these changes and query the extent to which the changes amount to a transformative pedagogy recognizing home and community as a significant source of and place for learning. It is argued that cultural knowledge and family practices have not been sufficiently acknowledged and utilized in the current practices associated with the learning-from-home event. Based on the notion of funds of knowledge, we argue that a transformative pedagogy should build purposeful connection between school curriculum, cultural knowledge and family practices. This approach is illustrated using an example of play-based learning where a parent engaged her Year 4 daughter in a home café enabling informal learning that met the requirements of the school curriculum. This case invites further reflection on important questions related to what counts as learning and what worthwhile learning encompasses.
\end{abstract}

Best Evid Chin Edu 2020; 5(2):635-648.

Doi: 10.15354/bece.20.or023.

How to Cite: $N g$, C., Renshaw, P. (2020) Transforming pedagogies in Australian schools amid the COVID-19 pandemic: An activity theoretic reflection. Best Evid Chin Edu, 5(2):635-648.

Keywords: COVID-19; Online Learning; Pedagogy; Educational Change; Activity Theory; Funds of Knowledge. 


\section{Introduction}

6 LEARNING from home" has made it possible for Australian students to continue their education despite school closure amid the COVID-19 pandemic. 'Learning from home' encompasses different forms of flexible learning arrangements, including online learning, using paper-based learning packages or a combination of both online learning and paper-based materials. In this paper, we reflect on pedagogical changes associated with 'learning from home' arrangements in response to the coronavirus outbreak in Australia during the period between March and May 2020. We draw on Engeström's third generation activity theory that situates pedagogy as part of an evolving activity system (Engeström, 1987, 2001, 2007). Pedagogy is defined, not as a set of teaching skills, but as a structured process wherein acts of teaching are mediated by a set of rules, interactions, and use of tools for achieving valued outcomes. This definition highlights the social and contextual nature of pedagogy. It aligns with Vygotsky's sociocultural understanding of learning and teaching, which Renshaw (1998, p.83) considered important, as 'it situates learning (and teaching) as an aspect of interrelated historical, cultural, institutional, and communicative processes'. Adopting this contextualized perspective, we consider pedagogical changes associated with the learning-from-home event, which, owing to its unprecedented scale, can be taken as an example epitomizing, what Renshaw (1998, p.83) described as, 'novel forms of collective action and community participation that the technologies support'. In this reflection, we highlight the question of novelty in relation to pedagogical transformation amid the learning-from-home event, examining the extent to which this novel form of collective action has triggered 'novel ways of acting, feeling and thinking' about pedagogies.

In the sections that follow, we describe first how education authorities in Australia responded to the pandemic and in what ways 'learning from home' were taken as a temporary solution to school closure. Based on cultural-historic activity theory (CHAT), we then argue that due attention has not been given to utilizing home resources (in addition to computing and internet technologies) and parental involvement as core components of a transformative pedagogy addressing educational exigencies due to the pandemic. At the time of writing, Australian jurisdictions were re-opening schools. Although the learning-from-home phenomenon is not perennial, home resources, parental involvement and student agency are important features that can remain and be incorporated into teachers' pedagogical repertoire. The COVID-19 pandemic provided a rare opportunity to reflect on current practices and reconsider significant pedagogical elements that could transform the learning and teaching processes.

\footnotetext{
About the Author: Peter Renshaw, Professor, School of Education, University of Queensland, Brisbane, QLD 4072, Australia.Email:p.renshaw@uq.edu.au.

Correspondence to: Clarence Ng, Associate Professor, Institute for Learning Sciences \&; Teacher Education, Australian Catholic University, Level 4, 229 Elizabeth Street, Brisbane, QLD 4000, Australia. Email: clarence.ng@acu.edu.au.
}

Conflict of Interests: None. 


\section{COVID-19 Outbreak in Australia and School Closure}

In Australia, school closures began in late March 2020, following a wave of pandemictriggered restrictions including social distancing requirements, business closures, travel bans, and compulsory quarantine of travelers returning from overseas. Despite school closure, Scott Morrison, the Prime Minister, insisted that learning should be continued.

'One thing that I know teachers are united on, with their parents, is we do not want one of those things to be the loss of a child's education, giving up a whole year of their learning' (SBS News, 15 April 2020).

Education authorities in different Australian jurisdictions supported this stance wherein the concern about 'a loss of learning' justified creative arrangements to enable 'learning from home'. Complicating this novel education scene was that children of essential workers, such as medical professionals, were allowed to attend school, resulting in two cohorts of students - those who learnt from home and those who attended school. In this discussion, our concern was about the majority group of students who continued education using the mode of 'learning from home'.

The term 'learning from home' refers to different kinds of flexible learning arrangements that schools and teachers used to assist students to continue education at home. These flexible arrangements include online learning, using of pre-set learning packages, televised lessons, and their combinations. Teachers put together learning materials enabling learning through paper-based and online-based modes over a short period of time while the threat of coronavirus infection intensified. This involved redesigning lesson plans and resources, careful structuring of learning activities, and developing new assessment tasks for online and self-guided or parent-guided learning. It was indeed a professional feat as Australian teachers made this possible within a short time amid the outbreak, which has inevitably fomented teachers' concerns about unexpected workloads (Heaney \& Breen, 2020). Recognising the immensity of tasks associated with 'learning from home', education authorities across the country have provided urgent support and advice in relation to sample lesson plans, design of online learning activities and learning packages, and guidelines for delivering online lessons or 'learning from home' (see an example of departmental guidelines from Queensland, https://education.qld.gov.au/curriculum/learning-at-home; see examples of learning packages from New South Wales, https://education.nsw.gov.au/teaching-and-learning/ learning-from-home/learning-at-home/learning-packages). In Queensland, the Department of Education partnered with different TV networks to deliver televised lessons for lower primary and pre-school students in order to assist parents with 'learning from home', especially those who did not have IT skills or were disadvantaged due to cultural, economic and linguistic constraints. Parental guidelines were provided to encourage parents to minimize distraction, provide learning spaces, and manage screen time and online safety for their children (see an example of parental guidelines from Victoria, https://www.education.vic.gov.au/parents/learning/Pages/home-learning.aspx). In many cases, parents were expected to play the role as a monitor to ensure that online lessons and learning activities were completed in accordance to a set plan (see ABC News, 
2020a). Students' engagement and attendance through online learning were monitored (Kelly, 2020). In some cases, students were told that their parents would be informed if they did not finish all the learning tasks diligently. For students who did not have computing devices for online learning or who did not have internet access at home, the departments of education and charitable organizations across the country offered internet dongles and mobile devices to many disadvantaged students. Nevertheless, the issue of digital divide remained the most pressing concern amid the pandemic. In particular, the negative impact on disadvantaged students was pronounced, as 'only $68 \%$ of Australian children aged 5 to 14 living in disadvantaged communities have internet access at home, compared to $91 \%$ of students living in advantaged communities' (Graham \& Sahlberg, 2020).

'Learning from home' has indeed magnified some perennial educational problems in Australia, such as digital gap, educational inequalities, and literacy underachievement. To evaluate the effects of school closure on students from vulnerable backgrounds, the Federal Government called for a series of quick research and expert reports (e.g. Lamb, 2020; Masters, 2020) to examine critical issues such as digital divide, educational inequality and achievement gaps. These reports highlighted risks for vulnerable students from various disadvantaged backgrounds of falling further behind in academic achievement compared to their advantaged counterparts during the pandemic (Duffy, 2020). A significant decision made by the Federal Government, in response, was to cancel the national test of literacy and numeracy (NAPLAN) that was originally scheduled to conduct in May 2020.

Importantly, the learning-from-home initiative has revealed core elements of education in Australia. First, teachers were recognized and celebrated for their crucial role in educating children (ABC News, 2020b). Such recognition is in marked contrast to a decade of policy focus on top-down accountability that fostered mistrust of the teaching profession. Teachers' professionalism, generosity and care for the students were widely acknowledged and celebrated in the media during school closure. Second, the cancellation of the national test of literacy and numeracy amid the pandemic indicates that national tests such as NAPLAN have limited value in progressing learning for individual students. In this unprecedented time, the most important task was to enable meaningful learning to continue, but not testing, though an important concern was how best to assess Year 12 students and facilitate selection for university education. Third, home remains the most important place for learning to occur. In this sense, the government has rightfully sought expert advice on facilitating 'learning from home' for vulnerable students from disadvantaged backgrounds. This of course highlighted the problem that some homes are less conducive to learning than others. Due attention, however, has not been given to positioning home, a significant place of education, as a solution or part of the solution to complex educational issues. The pandemic has inadvertently set a spotlight on 'home' as a significant source of and place for learning. This means that any meaningful solution needs to consider influences derived from home and ways that the home can be incorporated in the solution designed to overcome the problem of school closure. 


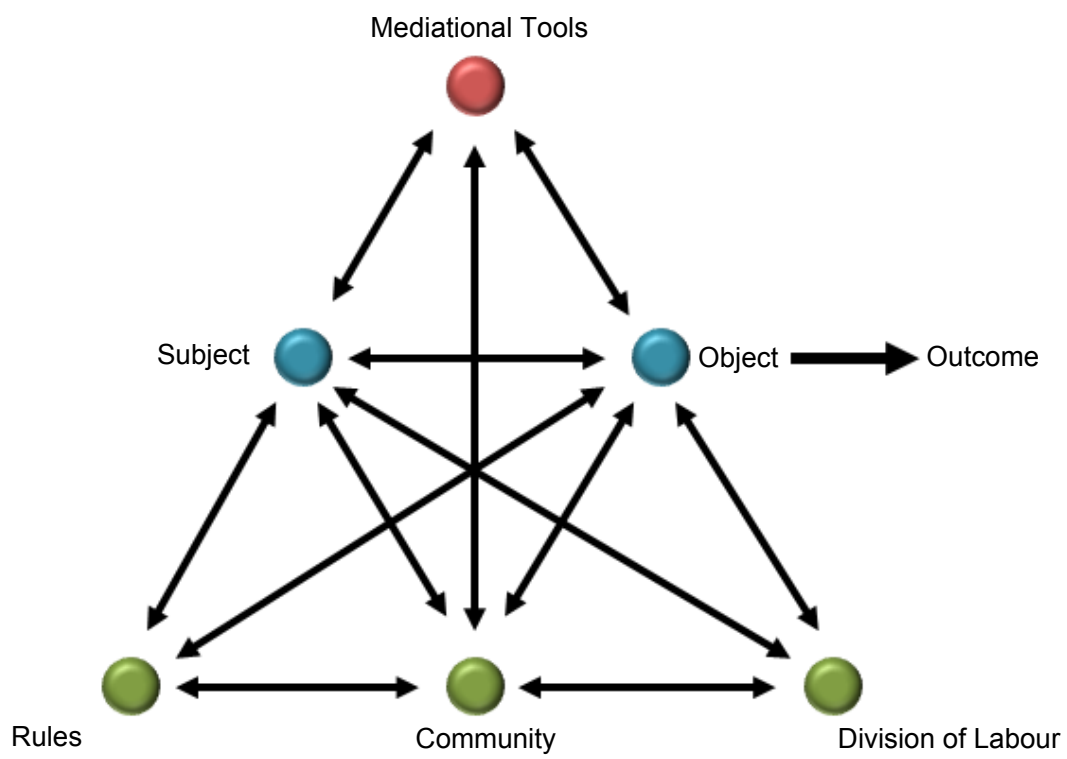

\section{Figure 1. A Triangular Representation of An Activity System.} (adapted from Engeström, 1987, p.78)

\section{Reflecting on Pedagogy for "Learning from Home" Using Activity Theory}

The pandemic has made it possible to experiment with online delivery of school education at a large scale in a short period of time. As education researchers, we are interested in reflecting on the systemic change in practice and exploring how the pandemic might facilitate a rare opportunity for transforming pedagogies. The key questions are: What has been changed? Were these changes transformative? These questions are important as we may face a second wave of infection and there is a need to prepare for another unpredictable event that may lead to school closure.

We draw on Engeström's cultural-historic activity theory (CHAT) to assist our reflection and exploration. CHAT is used because it conceptualizes pedagogy not as a set of teacher skills but as contextualized actions and practices in an activity system. Importantly, CHAT alerts us to take a holistic perspective to pedagogy by examining it as an emergent process derived from the interaction between components of an activity system as a whole. CHAT draws attention to the dynamic link between what teachers are trying to achieve, what they do, how students learn and resist learning, how other 
stakeholders contribute to learning/teaching, and how norms and rules are implemented and resisted. Figure 1 shows a triangular representation of a typical activity system that Engeström used to highlight essential nodal components of an activity system. These nodal components include subject, object, tools, rules, division of labour and a community. Human actors (subjects) interact with each other using relevant cultural tools in their participation in an 'activity' in order to achieve a shared goal (an object) which is arguably the most important element separating one activity system from another. Actors' interaction and mediated use of tools are governed by norms and values (rules) agreed between the members (community) who share a common interest on the object and play different roles within an activity system (division of labour). It should be noted that the whole activity system is always in a dynamic state fraught with contradictions, as members interact with each other to achieve a goal that might be understood in different ways. An activity system is therefore "the minimal meaningful context" for understanding human actions and development (Kuutti, 1996, p.28).

Using CHAT, we are able to avoid a reductionistic treatment of pedagogy, as it draws our attention to multivoicedness (different members), historicity and continuity (enduring institutional goals and practices) in pedagogical construction and development. Pedagogical change may involve a new educational goal, use of new technologies or a new curriculum, new rules (e.g. pre-requisite for university entrance), new partners who assume a particular role, and the dynamic interaction between new and extant elements in a pedagogical activity system. Pedagogical change, therefore, is an uncertain venture wherein contradictions and tensions abound, as teachers, students and other members interact and adjust with each other during the introduction of a new pedagogical element. Negotiation is inherent to the process of pedagogical change and resolving successfully contradictions and tensions is critical for genuine pedagogical transformation $(\mathrm{Ng}, 2009)$.

From a CHAT perspective, major pedagogical changes during the learningfrom-home event involve the following areas:

1. Mode of delivery changes from face-to-face interaction to online delivery or working remotely on pre-packaged materials;

2. Lesson context changes from classroom-based activities to home-based activities;

3. Teacher's role changes from classroom instructor to online instructor and designer of pre-packaged/online curriculum materials;

4. Student's role changes from learning in a face-to-face interactive context in the classroom to learning individually using self-contained materials or participating remotely on online platforms;

5. Parent's role expands to encompass supporter, monitor and regulator of child's online learning or other forms of 'learning from home' activities;

6. Multimodal literacy strategies are required for effective interactions between peers, and between students and teachers during online learning.

To examine the extent to which the classroom-based pedagogical system has been transformed, it is not sufficient to examine changes at a particular node (see Figure 
1). Any pedagogical change needs to be considered in the context of interconnected relationships between individual nodes within an activity system. Therefore, pedagogical change during the pandemic is not just a question of students' access to the internet and the quality of internet connection at home. Additional questions include: Are students prepared for online learning? What forms of support are available from teachers, peers and parents? What forms of interaction are promoted on online platforms? What kinds of learning outcomes are privileged in online materials? From a teacher's perspective, the question goes beyond the quality of re-designed learning materials provided to students via an online platform. Additional considerations include whether teachers have the required knowledge and skills to assume the role of online instructor and what capabilities they have developed to teach effectively in an online environment. More importantly, as 'learning from home' assumes parental involvement, the extent to which teachers understand how to involve parents in online learning and home-based learning is crucial for successful delivery of 'learning from home'. From a parent's perspective, the key concern is not just whether internet and computing devices are provided to their children. It is also important to examine whether parents feel comfortable to take on new roles as a monitor and supporter of online learning or home-based learning. Parents' knowledge and skills of online learning and their understanding of school curriculum are critically important to supporting their children's online learning and other forms of 'learning from home' activities. Furthermore, worries and concerns from teachers, students and parents about these changes need to be dealt with. Taken together, successful and transformative change is not simply a matter of putting materials online or ensuring students' online attendance as scheduled.

Has the pandemic enabled the emergence of a new form of pedagogy stretched across home-school contexts and mediated by online technologies and materials? The key to answering this question is to examine the object within an activity system, which, as explained above, is an important element that separates different activity systems. This is because it is through the object that different component elements are designed and related to each other. Importantly, the object signifies what is worthwhile pursuing and what is being valued as an outcome in an activity system. It seems to us that during the 'learning from home' period, the object of teaching and learning remained unchanged (though setting up online platform and developing learning packages can be taken as a transient object at the initial stage of school closure). Teachers and schools still focused on the extant curriculum goals. For example, scholars (see https://www.dese.gov.au/covid-19/schools) who were commissioned by the Australian Government to write short research reports on the effects of home-based learning during the pandemic, framed their responses in terms of 'loss of learning' and 'widening gaps'. They deployed metrics to describe the loss in terms of the number of months or terms of a normal school year (see for example, Lamb, 2020; Masters, 2020). This reveals that for policymakers the learning-from-home event was an aberration from the standard form of schooling. This of course became problematic. Worries and tensions were unavoidable as teachers, principals and parents wondered how 'learning from home' could ensure steady progress of learning as set out in the national curriculum 
(ABC News, 2020a; Heaney \& Breen, 2020). Unsurprisingly, in many cases, 'learning from home' involved an identical lesson schedule and similar teaching routines used in classroom-based instruction, which of course, made it hard for students to maintain engagement when they were expected to sit through a day's lessons in front of a computer or a mobile device, though younger children might have had more freedom regarding how they engaged in a lesson under the supervision of their parents (ABC News, 2020a). Parents responded anxiously to the narrative of loss of learning measured against preset curriculum standards. Asking parents to monitor students' engagement in online learning or completing pre-set learning activities at home, as reported repeatedly in the media, created anxieties and increased conflicts with their children (Fisher, 2020). Migrant parents faced additional challenges due to cultural differences, language barriers and limited knowledge about the Australian educational systems (Yang et al., 2020). Our view is that the legitimate and significant role of 'home' as a source of and a place for learning has not been acknowledged sufficiently in the learning-from-home initiative. Below we discuss this case of missed opportunity based on the notion of funds of knowledge (Gonzalez et al., 2006).

\section{A Missed Opportunity}

The pandemic offered a rare opportunity for reconsidering pedagogy and change. In addition to critical issues such as teachers' technological pedagogical content knowledge (TPACK) and effective use of social media and internet resources, an important point of consideration is the extent to which resources and practices derived from home and relevant communities can be incorporated into the learning and teaching processes in order to develop a transformative pedagogy. From a CHAT perspective, home-based and/or community-based resources and practices can be taken as cultural tools for learning. Linking the school curriculum with valued knowledge and practice at home and in the wider community can create a problem space for negotiating a shared object or valued outcome in a pedagogical activity system. This is a problem space because teachers' epistemological beliefs about valued knowledge and how best to teach it will be challenged when deliberate connection is made to link school curriculum with cultural knowledge and practices derived from home and wider communities. In this form of transformative pedagogy, students are no longer receivers of knowledge controlled by the teacher; they too are legitimate knowers with access to, and experience of cultural knowledge and practices. Parents can be expected to play an important role as an expert knower assisting their children to make sense of knowledge about a school subject from a cultural perspective, sharing their experiences and understanding.

Related to this proposal is the concept of and research on funds of knowledge (FoK). FoK is "a systematic and powerful way to represent communities (including home) in terms of resources, the wherewithal they possess and how to harness these resources..." (González et al., 2006, p.x). FoK includes, but is not limited to, language practices, social relationships, knowledge about culture, histories and local environments and a set of strategies for getting things done. This concept bridges the gap between school and home and enables theorization of pedagogy based not on the teacher's 
own knowledge of the curriculum but also 'the lives of ordinary people, their everyday activities and what has led them to the place they find themselves' (González et al., 2006, p.1). Importantly, this approach 'allows for variability within populations' and 'the infinite variations that social agents are able to negotiate within a structure' (González et al., 2006, p.43). In other words, FoK acknowledges diversity, respects agency and values localized knowledge. More significantly, González emphasizes that FoK is formed and transformed within sociohistorical circumstances and constructed through discourses. From this perspective, any form of 'learning from home' needs to consider (i) In what ways localized knowledge can be connected with school curriculum; and (ii) How to utilize FoK to promote a dialogue in order that school learning and family practices are related in sensible and meaningful ways. In this way, students and their families are positioned as knowledgeable partners in the course of delivering 'learning from home'. This will also help bridge the divide between school and home, and avoid a deficit view of learning, especially for students coming from culturally and linguistically diverse communities or economically disadvantaged families. In this context, Rodriguez (2103) alerted us to the issue of power imbalance in advancing FoK pedagogical designs. More recently, Llopart and Esteban-Guitart $(2017,2018)$ have reviewed FoK pedagogical designs that addressed power relationship and purposefully connected cultural knowledge and family practices to school curriculum.

\section{An Illustration}

At this point we want to illustrate how FoK can be part of the learning-from-home process using a news article reported in the ABC news, dated 27 April 2020 (Parker, 2020). In this article, an Australian parent, named Rachel Parker, recounted her worries about 'learning from home' and how she greeted with tears what her Year 4 daughter, Lila, called the 'mummy school'. Rachel, Lila and other family members experienced the rigidness of 'learning from home' as Lila shouted 'shut up' to all her family members at the commencement of her online lesson. Though the news article did not depict a detailed account of all the worries that Lila and the family had experienced as a result of 'learning from home', Rachel's thought of needing to 'get out of here' and to take a walk with Lila in the nearby park epitomized her frustration.

As the pair walked through the park, Rachel engaged Lila in an educational chat about different creatures they encountered. They saw flying bugs and Rachel raised a question about 'what are they? Will they bite?'. They saw other dogs and Lila asked the owner 'do they shed?'. They were puzzled to see a truck with a barrel of chemicals and a spray gun and wondered what it did. Lila thought it might be related to the outbreak. Rachel and Lila continued to talk about what they had seen as they returned home.

The day continued for Lila and the family, not following the scheduled online lessons, but through a pretend play of running a home café for the family members. Lila initiated the home café after watching a YouTube video of a girl who started a restaurant in her driveway during the pandemic. Lila, as the chef, created a menu for her mother to read. Playing the role as a waitress, Lila took order from Rachel and her elder 
sister, calculated the price and served them in a physical setting observing social distancing rules. Lila assigned Rachel to play different roles including servant, cleaner and IT helpdesk. Rachel, in her role as an IT employee, helped Lila re-design the menu using the photos of food and drinks they took, showed her how to use Word and email, and how to use different Word functions to type and price new items. The pair discussed operating costs, pricing, and discounts. They watched YouTube videos on decimals, fractions and percentages in order to work out discounts for the family members. They also decided to donate the profits to a hospital for purchasing surgical masks. As a customer, Rachel wrote a review of the café for Lila to read.

Rachel, in her reflection, considered Lila's learning during the day met the Year 4 English curriculum that requires students to create texts using software and multimodal sources. It also covered the Year 4 Mathematics curriculum of learning fractions and decimals and using them in relevant contexts. She concluded that her experience of 'learning from home' could serve as a reminder that 'we might use parts of our ordinary lives as the canvas to paint a simple picture of learning through play at home'.

From a FoK perspective, this play-based case illustrates that home is an important source of and place for learning. Home furniture, kitchen equipment, home space, and computer and internet resources were re-organized and redeployed to enable play-based learning of a home café. Notably, the short walk in the park and an engaging talk about creatures they encountered set the scene for Lila to free up her creative mind and for Rachel to see alternative learning possibilities. Rachel, as the parent, played an important role enabling, facilitating and participating in meaningful learning that met Lila's needs and simultaneously addressed the requirements of the school curriculum. This was a stark contrast to the role of monitoring children's learning and ensuring time-on-task that the school expected parents to take. Creativity, flexibility and involvement are keys to success, as demonstrated in Lila's play-based learning. A rather different picture would have evolved if Rachel had insisted Lila to follow the school's rigid schedule of learning which specified the exact time that Lila was required to work on literacy, mathematics and other subjects on a daily basis.

This case outlines a transformative pedagogy utilizing home resources and parental involvement based on play-based scenarios. Teachers, of course, need to understand and gather students' FoK before they can incorporate cultural knowledge and family practices as part of a transformative pedagogy. FoK researchers have achieved this through ethnographic studies involving home visits and interviewing parents (e.g. González et al., 1995; Kiyama, 2010). Other researchers have explored students' FoK through classroom discourse and interaction (e.g. Barton \& Tan, 2009; Moje et al., 2004). Another important consideration is how to connect family practices to school curriculum. Addressing this issue, Llopart and Esteban-Guitart (2017) have reviewed an array of studies to show how student-produced artefacts such as photographs, texts and digital productions can be utilized to develop a pedagogy building on students' cultural knowledge and experiences. Critical to school-home connection is the question of what can be counted as learning. In the case of Lila's play-based learning, Rachel considered play-based learning favourably, while Lila's teenager sister held a different view and 
commented that it was not 'real learning'. This tension could be generative if it opened up the problem space for reconsidering the object of a pedagogical activity system, i.e. what counts as valued knowledge and outcomes. Due attention should be given to the issue of power asymmetry inherent in this tension, as students and parents are always positioned at the receiving end of education (Rodriguez, 2013). The case of Lila's playbased learning, aligned with FoK studies reviewed by Llopart and Esteban-Guitart (2018), speaks against treating students and parents from a deficit perspective. As shown in Lila's case, curriculum knowledge can be developed through meaningful activities at home (e.g. calculating discounts using fractions for family members) where students and parents are legitimate knowers. Connecting school curriculum with family practices can only be taken as an effective design principle for developing transformative pedagogies when cultural knowledge and family practices are rightfully respected and utilized to enrich school learning.

\section{Conclusion}

In this paper, we have reflected on 'learning from home' as a novel collective response to the pandemic in Australia. We focused on pedagogy as the main issue because pedagogy is at the heart of all forms of learning, whether it occurs in the classroom, at home or on online platforms. Under the sway of neoliberal policies current pedagogical practices have become closely aligned with reductive accountability metrics. A good example is the concern about a loss of learning during the pandemic. In response, 'learning from home' that was supposed to be a flexible means to meet students' diverse needs, was taken as a conduit for the curriculum using rigid daily routines and schedules. We argued that this was a missed opportunity for transforming extant pedagogies and redesigning how home and parents could contribute to the pedagogical process.

'We are in this together' is a narrative widely used in the Australian media urging mutual support and care during the pandemic. If we are truly in this together, then the 'we' needs to include everyone. Following this narrative of togetherness, a transformative pedagogy, responding to the exigencies of a shared challenge posed by the pandemic, calls for a focus on diversity and cultural resources at home and in different communities. Losing sight of support on learning derived from home resources and parental involvement may result in a form of 'learning from home' that is decontextualized, rigid and disengaging. By understanding learning that diverse students may engage in outside the classroom and by creating ways for these lived experiences of learning to be woven into the curriculum and classroom activities, we may be able to transform our pedagogy with a focus on multiple contributors and partners within a reconfigured activity system, bringing partners together, working collaboratively towards a shared goal and outcome of education. In doing so, such a transformative pedagogy hinges not just on how well teachers are prepared or knowledgeable about the curriculum, but also how students and parents can be a curriculum partner bringing their resources and knowledge to enliven a curriculum text in their own lived environment. The pandemic provides a chance for us to reflect on a transformative pedagogy. Engeström's CHAT alerts us to the importance of developing a shared vision based on 
broadened understanding of knowledge and learning; where students, parents and teachers together negotiate the curriculum; and where multiple voices and localized practices are valued. In this way, we propose a vision of connected learning linking school and home at the post-pandemic world. Essentially, this form of new learning is agentic, intergenerational, participatory and multicultural in nature.

\section{References}

ABC News. (2020a, April 18) Learning from home during coronavirus is a new challenge. So how are parents organising the school day? Retrieved from https://www.abc.net.au/news/2020-0418/home-based-learning-tips-for-parentscoronavirus-australia/ 12154578

ABC News. (2020b, April 27) Teachers head to the classrooms on a wave of \#TeachersRock support following coronavirus shutdown. Retrieved from https://www.abc.net.au/news/2020-0427/coronavirus-teachers-return-to-schoolcelebrities-show-support/12188268

Barton, A. C., \& Tan, E. (2009) Funds of knowledge and discourses and hybrid space. Journal of Research in Science Teaching, 46(1), 50-73. doi:10.1002/tea.v46:1

Duffy, C. (2020, April 28) Five reports on remote learning find vulnerable students could fall six weeks behind due to COVID-19-related measures. ABC News. Retrieved from https://www.abc.net.au/news/2020-0428/vulnerable-students-could-fall-behindremote-learning-covid19/12190834

Engeström, Y. (1987) Learning by expanding: An activity-theoretical approach to developmental research (2nd ed.). New York, NY: Cambridge University Press.

Engeström, Y. (2001) Expansive learning at work: Toward an activity theoretical reconceptualisation. Journal of Education and Work, 14(1), 133-56.

Engeström, Y. (2007) Enriching the theory of expansive learning: Lessons from journeys towards coconfiguration. Mind, Culture and Activity, 14(1-2), 23-39. https://doi.org/10.1080/107490307013076 89

Fisher, T. (2020, May 20) Getting to the end of homeschooling during coronavirus (without losing it). ABC News. Retrieved from https://www.abc.net.au/life/gettingto-the-end-of-homeschooling-duringcoronavirus $/ 12210588$

González, N., Moll, L. C., \& Amanti, C. (Eds.). (2006) Funds of knowledge: Theorizing practices in households, communities, and classrooms. New York:

Routledge.

González, N., Moll, L. C., Tenery, M. F., Rivera, A., Rendon, P., Gonzales, R., \& Amanti, C. (1995) Funds of knowledge for teaching in Latino households. Urban Education, 29(4), 443-470.

Graham, A. \& Sahlberg, P. (2020) Schools are moving online, but not all children start out digitally equal. The Conversation. Retrieved from https://theconversation.com/schools-aremoving-online-but-not-all-children-startout-digitally-equal-134650

Heaney, C. \& Breen, J. (2020, April 9) Teachers face 'unreasonable workloads' preparing for coronavirus impact on term 
$\mathrm{Ng} \&$ Renshaw. Transforming Pedagogies in Australian Schools amid the COVID-19 Pandemic.

two, union says. ABC News. Retrieved

from https://www.abc.net.au/news/2020-

04-09/coronavirus-education-nt-teachers-

workload-pandemic/12136538

Kelly, M. (2020, April 10) NSW Department of Education monitors online learning engagement. The Canberra Times. Retrieved from

https://www.canberratimes.com.au/story/ 6718833/students-being-marked-absentfor-not-engaging-with-onlinelearning/digital-subscription/\#gsc.tab $=0$

Kiyama, J. M. (2010) College aspirations and limitations: The role of educational ideologies and funds of knowledge in Mexican American families. American Educational Research Journal, 47(2), 330-356.

Kuutti, K. (1996) Activity theory as a potential framework for human-computer interaction research. In B. Nardi (Ed.), Context and consciousness: Activity theory and human computer interaction (pp. 17-44). Cambridge, MA: MIT Press.

Lamb, S. (2020) Impact of learning from home on educational outcomes for disadvantaged children: Brief assessment. Retrieved from https://www.vu.edu.au/sites/default/files/i mpact-of-learning-from-home-federalgovernment-brief-mitchell-institute.pdf

Llopart, M., \& Esteban-Guitart, M. (2017)

Strategies and resources for contextualising the curriculum based on the funds of knowledge approach: a literature review. Australian Educational Researcher, 44(3), 255-274. https://doi.org/10.1007/s13384017-0237-8

Llopart, M., \& Esteban-Guitart, M. (2018) Funds of knowledge in 21 st century societies: Inclusive educational practices for under-represented students. A literature review. Journal of Curriculum Studies, 50(2), 145-161.

https://doi.org/10.1080/00220272.2016.12 47913

Masters, G. (2020) Ministerial briefing paper on evidence of the likely impact on educational outcomes of vulnerable children learning at home during COVID-19. Re- trieved from

https://research.acer.edu.au/cgi/viewconte nt.cgi? article $=1025 \&$ context $=$ learning_pr ocesses

Moje, E. B., Ciechanowski, K. M., Kramer, K., Ellis, L., Carrillo, R., \& Collazo, T. (2004) Working toward third space in content area literacy: An examination of everyday funds of knowledge and discourse. Read Res Quarterly, 39(1):38-70.

$\mathrm{Ng}$, C. (2009) Exploring the linkage between reforms and learning in the Asia-Pacific region: An Activity Theory perspective. In Ng, C. \& Renshaw, P. (Eds)., Reforming Learning (pp. 23-40). Dordrecht, the Netherlands: Springer.

Parker, R. (2020, April 27) When coronavirus forced me to home-school my daughter, learning through play was the answer we both needed. ABC News. Retrieved from https://www.abc.net.au/news/2020-0427/coronavirus-homeschool-learningthrough-play/12167528

Renshaw, P. D. (1998) Sociocultural pedagogy for new times: Reframing key concepts. Aust Edu Res, 25(3):83-100.

Rodriguez, G. M. (2013) Power and agency in education: Exploring the pedagogical dimensions of funds of knowledge. Rev Res Edu, 37: 87-120.

SBS News (2020, April 15) Prime Minister Scott Morrison has thanked Australian teachers as he calls on them to keep classrooms operating with students preparing to start term two. Retrieved from https://www.sbs.com.au/news/scottmorrison-issues-direct-plea-to-australia-steachers-urging-them-to-keep-theirclassrooms-open.

Yang, S., Chamas, Z. \& Souisa, H. (2020, April 17) Migrant parents in Australia face challenges posed by home learning model amid coronavirus pandemic. ABC News. Retrieved from https://www.abc.net.au/news/2020-0417 /migrant-parents-face-challengesduring-coronavirus-homelearning/12154036. 
Ng \& Renshaw. Transforming Pedagogies in Australian Schools amid the COVID-19 Pandemic. Received: 16 June 2020 Revised: 18 June 2020 Accepted: 18 June 2020 